\title{
A mediação da informação na Casa Abrigo da Paraíba: o protagonismo das mulheres no enfrentamento à violência doméstica
}

\author{
Aurekelly Rodrigues da Silva \\ Doutoranda; Universidade Federal da Paraíba, João Pessoa, PB, Brasil; \\ aurekelly@ hotmail.com \\ Gisele Rocha Côrtes \\ Doutora; Universidade Federal da Paraíba, João Pessoa, PB, Brasil; \\ giselerochacortes@gmail.com
}

\begin{abstract}
Resumo: A pesquisa objetiva verificar como a mediação da informação na Casa Abrigo da Paraíba favoreceu o protagonismo das mulheres para romper com a situação de violência doméstica. Quanto à metodologia, o estudo tem caráter descritivo, com abordagem qualitativa, para cujo desenvolvimento foi utilizado como estratégia o estudo de caso. O campo de pesquisa foi a Casa Abrigo da Paraíba e as interlocutoras foram mulheres que acessaram o órgão. Na coleta, utilizou-se a entrevista em profundidade, realizada com mulheres que se encontram privadas de sua liberdade, e que precisaram recorrer a um abrigo para se manterem vivas. Os dados foram analisados utilizando-se a análise de conteúdo. Os resultados demonstram que a Casa Abrigo da Paraíba é um espaço crítico, de dialogia, criatividade e alteridade, no qual a mediação da informação é consciente e constante com o intuito de ressignificar a violência vivenciada pelas mulheres acolhidas na Casa. Constata-se que a mediação dos conteúdos informacionais dinamizados pela Casa Abrigo da Paraíba contribuiu no desenvolvimento do protagonismo das mulheres, impactando nas percepções sobre a violência doméstica e o rompimento com o ciclo de violência. Quanto ao protagonismo das mulheres, este pôde ser constatado na resistência e luta para romper com a situação de violência desde o momento que elas buscaram ajuda e foram direcionadas para o órgão. Finaliza-se considerando que a informação mediada conscientemente pode ser uma das vias para mudança de mentalidades e reversão dos diversos problemas existentes em nossa sociedade, que ainda é regida pelo machismo, pelo racismo e pela desigualdade social.
\end{abstract}

Palavras-chave: Mediação da Informação. Protagonismo Social. Violência Doméstica. Casa Abrigo. Mulheres.

\section{Introdução}

Considerada uma violação dos direitos humanos e o fruto das relações desiguais de poder entre homens e mulheres, a violência contra mulheres é um fenômeno 
transversal que ocorre em sociedades falocêntricas. A problemática ignora qualquer fronteira de raça/etnia, classes sociais, religião, grau de escolaridade e grau de desenvolvimento econômico, podendo ocorrer em qualquer etapa da vida das mulheres.

A violência doméstica, enquanto um dos tipos de violência contra mulheres, constitui qualquer ação ou omissão baseada no gênero que cause morte, lesão, sofrimento físico, sexual ou psicológico e algum dano moral ou patrimonial (BRASIL, 2006). Embora possa ser causada por qualquer pessoa que não seja necessariamente próxima ou conhecida da vítima e que ocorra em qualquer ambiente, esse tipo de violência é geralmente perpetrada no ambiente doméstico e familiar por agressores (homens que podem ser atuais ou excompanheiros) com os quais as mulheres agredidas mantêm ou já mantiveram algum tipo de relação afetiva (TAVARES; SARDENBERG; GOMES, 2011; WAISELFISZ, 2015). Esta é uma realidade que a categoria social mulheres enfrenta devido à naturalização de concepções hegemônicas de gênero que alocam às mulheres a situação de desigualdade social.

Historicamente, as mulheres têm sido protagonistas no processo de luta pela equidade de gênero ${ }^{1}$, no qual se destaca a conquista do direito à educação, ao voto e à igualdade de oportunidades. Não obstante, percebe-se a persistência de desigualdades em diversas esferas sociais, discriminação no mercado de trabalho, acesso à educação e representação política e entraves para a participação das mulheres na ciência (BORGES; OLINTO; LETA, 2014). Essas desigualdades estão imbricadas de forma intrínseca ao fenômeno da violência de gênero, sendo este um problema complexo, que envolve dimensões subjetiva, social, política e cultural.

Por décadas considerada uma questão de ordem privada, graças ao protagonismo dos movimentos feministas, a violência contra as mulheres tornou-se um problema público e político. Nessa seara, os movimentos feministas reivindicaram a criação de políticas públicas específicas para as mulheres, como, por exemplo, as Delegacias Especializadas de Atendimento à Mulher, os Centros de Referências e as Casas Abrigo - foco desta pesquisa - 
que objetivam reverter o cenário da violência, este engendrado uma sociedade predominantemente machista e misógina.

Nesse contexto, a informação, enquanto fenômeno social capaz de transformar culturalmente o ser humano e a sociedade, pode colaborar no processo de construção de novos contextos de significados. O acesso, a mediação e a apropriação da informação são pilares no enfrentamento do fenômeno da violência doméstica e ressignificação de conteúdos informacionais pautados em discriminações e opressões. Neste estudo, parte-se do pressuposto de que abordar o protagonismo social no campo da Ciência da Informação (CI) articula-se ao papel social da informação, pois o primeiro está intrinsecamente voltado à valorização da vida cidadã, com foco no respeito, na inclusão e na cidadania. Na visão de Gomes (2019), o protagonismo social está relacionado a uma postura, uma conduta e um modo de existência que abraçam todas as esferas da vida humana, nas suas várias dimensões, inclusive a cultural, sendo a cultura compreendida como a produção humana, na qual o objeto "informação" está incluído.

A partir dessa perspectiva, o presente estudo apresenta os resultados de pesquisa desenvolvida na dissertação de mestrado, realizada com mulheres, em risco iminente de morte em decorrência da violência doméstica, que acessaram a Casa Abrigo (CA) da Paraíba. Tal pesquisa buscou verificar como a mediação da informação na Casa Abrigo da Paraíba favorece o protagonismo das mulheres para romper com a situação de violência doméstica.

\section{Mediação da informação}

Nos últimos anos, inúmeras produções (FARIAS, 2014; LOUSADA, 2015; SANTOS NETO, 2014) foram empreendidas no escopo da CI a fim de conceituar a "mediação da informação". Algumas das concepções conceituais elaboradas por pesquisadores (as) da área, orientados por outras (os) autoras (es), possibilitaram refletir sobre a mediação da informação no desenvolvimento do protagonismo social, a exemplo de Gomes (2014, 2016, 2019). 
Segundo essa autora, a mediação da informação está direcionada para o protagonismo social, caracterizando-se como um ato de cuidar, sendo, portanto, uma ação relacionada a aspectos psicológicos, estéticos e éticos que envolvem o trabalho com a informação. Por isso, ressalta que a ação mediadora da informação representa um elemento essencial ao processo de desenvolvimento humano, no qual a dialogia é a base de sustentação. Destarte, a mediação precisa ser consciente para que, no processo dialógico, seja possível o exercício da crítica, responsável por tornar mais evidentes as lacunas existentes no estado de conhecimento humano e impulsioná-lo a estar no mundo como um agente de transformador da realidade.

$\mathrm{Na}$ literatura verifica-se a existência de distintas formas de conceituar a mediação da informação, a presente pesquisa caminha nas trilhas da definição proposta por Almeida Júnior ${ }^{2}$ (2015, p. 25, grifo nosso):

[...] é toda ação de interferência - realizada em um processo, por um profissional da informação e na ambiência de equipamentos informacionais -, direta ou indireta; consciente ou inconsciente; singular ou plural, individual ou coletiva; visando a apropriação de informação que satisfaça, parcialmente e de maneira momentânea, uma necessidade informacional, gerando conflitos e novas necessidades informacionais.

$\mathrm{Na}$ tentativa de ampliar as discussões atinentes à mediação da informação na CI trazendo como objetivo implícito dessa ação o desenvolvimento do protagonismo social, Gomes (2014, 2016, 2017) defende a existência de cinco dimensões da mediação da informação, que são elas: dialógica, estética, formativa, ética e política. Portanto, é imprescindível que o (a) mediador (a) reflita sobre essas dimensões no fazer informacional, pois, quando articuladas e alcançadas, são capazes de tornar a mediação da informação efetiva e propulsora do protagonismo social por meio da apropriação da informação (GOMES, 2019). Neste estudo, as cinco dimensões da mediação da informação exposta por Gomes (2014, 2016, 2017, 2019) serão utilizadas como parâmetro de análise para, então, refletir sobre as situações encontradas no campo da pesquisa. 
Compreende-se que a mediação da informação envolve ações de interferência, realizadas a partir de uma relação dialógica contínua, a qual envolve um (a) profissional mediador (a), um sujeito (singular, inserido em um contexto social) e a informação, visando a alterar o conhecimento existente e, ainda, possibilitando a construção de sentidos na medida em que os sujeitos se apropriam das informações mediadas. Por meio da ação consciente da mediação da informação, o protagonismo se torna possível, sendo este a última meta da ação mediadora (GOMES, 2019).

Segundo Almeida Júnior (2004, 2007), a apropriação da informação é dinamizada por meio do processo de mediação, e se constitui em uma ação não só de consumo, mas de produção que pressupõe alteração, transformação e modificação do conhecimento. Assim, ressalta-se que a apropriação da informação acontece quando a mediação da informação é efetiva, resultando, pois, no protagonismo social dos sujeitos, algo que será explanado a seguir.

\section{Protagonismo social}

Para tratar de protagonismo social toma-se como referências as obras de Edmir Perrotti e Ivete Pieruccini (2007), Edmir Perrotti (2017) e Henriette Gomes (2014, 2017, 2018, 2019). A proposta é compreender a gênese do conceito de protagonismo e discorrer sobre ele a partir de sua articulação com a informação e com o contexto do presente estudo: mulheres vítimas de violência doméstica acolhidas em Casa Abrigo.

Segundo Perrotti (2017), a gênese do conceito de protagonismo é observada na história de Antígona de Sófocles (496-409 a.C.). Uma mulher que, ao ver seus dois irmãos morrerem lutando em batalha, desafia o rei de Tebas, Creonte, por este não permitir o sepultamento de seu irmão, Polineices. Este foi considerado traidor da pátria por lutar em oposição ao rei, que ordenara deixar o corpo exposto para ser comido por aves de rapina. Antígona reage tentando realizar o funeral de seu irmão e usa as leis dos deuses que regem a vida da polis e dá direito à sepultura a todo cidadão como argumento perante Creonte. No entanto, furioso e desconsiderando as leis de Tebas, o rei a condena à morte e a 
sepulta viva em uma caverna subterrânea. Creonte coloca a esfera do privado acima da esfera pública e, a partir de então, várias desgraças passam a acontecer, gerando um período de violência que compromete a vida coletiva, inclusive a do próprio Creonte. O viver junto se tornou impossível naquela época e a relação entre os diferentes foi ficando comprometida. Assim, a conduta de Antígona em oposição ao rei Creonte passou a representar a esfera pública que se opõe contra a extrema elevação do privado, o qual tenta regular a 'vida comum'.

É nesse contexto que o conceito de protagonismo se fundamenta na valorização da vida cidadã, no reconhecimento do outro como pertencente ao todo sem distinção de qualquer aspecto, sendo o respeito a base da prática social. De acordo com Perrotti (2017), protagonismo é um termo multifacetado devido a sua riqueza semântica. $\mathrm{O}$ mesmo vem sendo usado em vários campos da ação social, especialmente na esfera das lutas por direitos de naturezas diferentes. O autor ressalta que "[...] protagonismo implica uma dimensão existencial inextricável. Significa resistência, combate, enfrentamento de antagonismos produzidos pelo mundo físico e/ou social e que afeta a todos [...]" (PERROTTI, 2017, p. 15).

Na perspectiva de Edmir Perrotti e Ivete Pieruccini (2007) e Henriette Gomes (2019), o termo protagonismo está ligado à luta, à resistência, à afirmação da participação na vida coletiva, e ele vem sendo utilizado em movimentos de resistência.

De acordo com Gomes (2019), após um processo de interpretação e significação, a informação se configura como elemento que torna possível compreender a realidade e as transformações causadas por ela na sociedade. Dito isso, a autora afirma que trabalhar conscientemente com a informação insere o protagonismo social e a mediação da informação no centro dessa atividade (GOMES, 2019). Partindo desses pressupostos, entende-se que, para ser protagonista, é necessário ter consciência da ação da informação e da sua capacidade de ressignificação.

O protagonismo se efetiva em espaços críticos de dialogia, alteridade e criatividade, locais que proporcionam a construção de diálogo, debates, dissenso e consenso em que os sujeitos vão expor e compartilhar pensamentos, opiniões e 
experiências de vida por meio de um processo comunicacional e interativo entre o (a) profissional e o (a) usuário, no qual acontece o acesso, uso e apropriação das informações mediadas nesses espaços (GOMES, 2017).

Nos espaços críticos, a ação comunicativa se efetiva desde que: todos (as) tenham espaço de voz, possam questionar e argumentar livremente; o debate seja aberto para problematizar a validade dos discursos de modo que não haja preconceitos, e sim respeito à alteridade. As subjetividades dos sujeitos como, por exemplo, sentimentos, atitudes e desejos - sejam expressadas sem restrições; e o direito de contestar, exigir ou permitir explicações manifestadas no estabelecimento de atos reguladores da vida ativa, do mundo da vida ou do sistema, enfim, da própria interação (GOMES, 2017). Com efeito, compreendese que a CA é um espaço crítico, de dialogia, que possibilita às mulheres o direito de falar, de expor seus pensamentos.

\section{Procedimentos metodológicos}

A pesquisa tem caráter descritivo, com abordagem qualitativa, para cujo desenvolvimento foi utilizado como estratégia o estudo de caso. Para Fonseca (2002) o estudo de caso permite ao pesquisador (a) conhecer com maior profundidade determinada situação, procurando descobrir o que há nela de essencial e característico. O campo de pesquisa é a Casa Abrigo e as interlocutoras são mulheres que acessaram o órgão.

Utilizou-se a entrevista em profundidade, realizada com mulheres que se encontram privadas de sua liberdade, e que precisaram recorrer a um abrigo para se manterem vivas. Ressalta-se que as entrevistas foram realizadas em local sigiloso, em ambiente externo à Casa Abrigo, e com escolta policial durante todo o processo. Os dados foram analisados utilizando-se a análise de conteúdo de Bardin (2010).

As mulheres entrevistadas serão identificadas neste estudo com os nomes de flores: (E1) Rosa, (E2) Margarida, (E3) Lírio, (E4) Orquídea e (E5) Girassol. 


\subsection{A Casa Abrigo}

A Casa Abrigo é uma moradia pública, protegida, temporária, com atendimento integral, e funciona como último recurso à mulher em situação de violência e que se encontra em risco iminente de morte. Tem capacidade para abrigar 20 mulheres e 10 crianças e/ou adolescentes, por um período de até 90 dias, prorrogável por igual período nos casos excepcionais e após avaliação da equipe multiprofissional ${ }^{3}$. Para acessar o órgão, é necessária a realização do Termo Circunstanciado.

Desde sua criação, em 2011, até o ano de 2018, a CA já realizou mais de 2.100 atendimentos e abrigou 156 mulheres e 248 crianças e adolescentes, como mostra o gráfico 1.

Gráfico 1 - Número de mulheres e filhos (as).

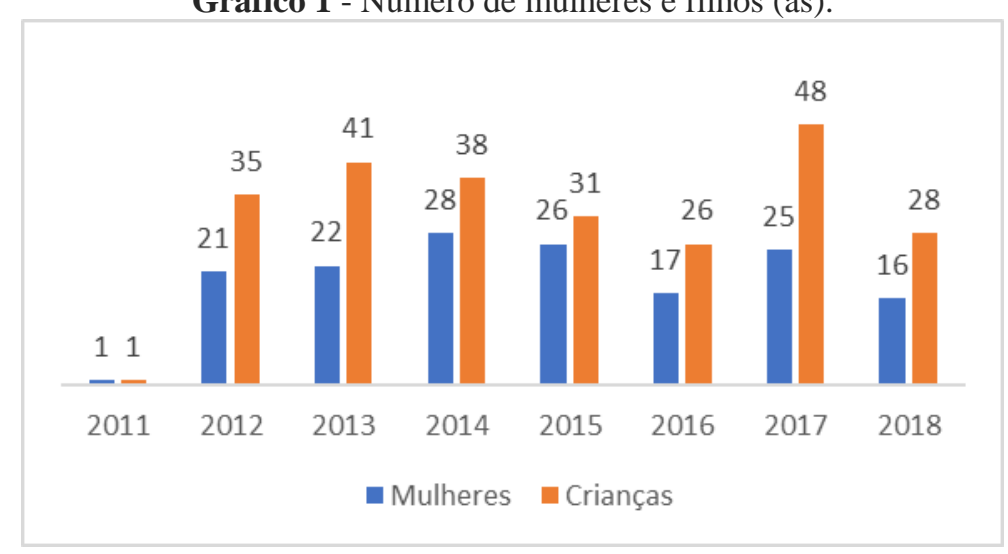

Fonte: Dados da pesquisa.

Sobre o perfil das mulheres atendidas na CA entre os anos de 2011 e 2018, constatou-se que a maioria delas possuem entre 18 e 25 anos de idade, são pardas, heterossexuais e viviam em união estável com o agressor, seu companheiro. No que tange à situação socioeconômica, ilustrada por meio da escolaridade, da renda e da ocupação, os dados mostraram que a maioria das mulheres abrigadas possui apenas o ensino fundamental incompleto, sobrevivem com até um salário mínimo, estão inscritas no Programa Bolsa Família e são trabalhadoras domésticas não remuneradas. No tocante à moradia, o maior quantitativo dessas mulheres reside em casas - que em sua maioria são imóveis alugados - localizadas na cidade de João Pessoa. 
A equipe de apoio da instituição caracteriza-se da seguinte forma: a coordenação, composta por duas coordenadoras (coordenação geral e coordenação administrativa); a equipe multidisciplinar (advogada, assistente social, educadora, arte educadora, psicóloga e enfermeiras); a equipe administrativa (agente administrativa, motoristas, cozinheira, auxiliar de serviços gerais); e a equipe de segurança, composta por policiais militares e policial de patrimônio.

Quanto aos serviços, a CA oferece atendimento integral e interdisciplinar às mulheres e aos seus (suas) filhos (as), em especial nas áreas pedagógica, psicológica, social e jurídica, promovendo condições objetivas de (re) inserção da mulher na sociedade. As ações da Casa Abrigo são conjugadas a programas de saúde, emprego e renda, moradia, educação, profissionalização, entre outros.

Quando a mulher deixa a CA, a equipe técnica faz o monitoramento pósabrigamento durante o período de três meses.

\section{Protagonismo das mulheres da Casa Abrigo no enfrentamento da violência doméstica}

Barreiras, obstáculos, impasses, dilemas e resistências. Apesar de sinônimos, essas são palavras que descrevem um pouco da vida de mulheres que vivem em situação de violência doméstica e que precisam recorrer a uma Casa Abrigo para se manterem com vida, seguras e distantes das agressões. Mulheres bonitas, mas escondidas pelas marcas da violência. Capazes, mas desmotivadas por não acreditar em si mesmas devido às desvalorizações constantes. Essa é a perspectiva de vida de algumas (a maioria) das mulheres que acessam uma Casa Abrigo.

Os dados apresentados a seguir foram extraídos por meio das entrevistas realizadas individualmente com cinco interlocutoras, as quais acessaram a CA da Paraíba. 


\subsection{História de violência}

As mulheres que buscam ajuda por vivenciar situação de violência doméstica carregam consigo uma história repleta de momentos difíceis, dolorosos e que marcarão para sempre suas vidas, e é por suas vidas que elas lutam quando vão para uma Casa Abrigo. Geralmente, são mulheres que sonhavam constituir famílias com alguém que compartilhasse experiências, desafios, vivências, enfim, a vida. Porém, os relacionamentos das interlocutoras foram marcados por violências.

Pensando nisso, solicitou-se às mulheres que contassem um pouco sobre suas experiências, e elas trouxeram relatos dolorosos nos quais as diferentes tipificações da violência doméstica estavam presentes.

Quadro 1 - Relatos sobre a violência vivenciada pelas mulheres acolhidas na CA.

[...] ele batia muito de mão mesmo, de soco. [...] xingamento e o mau trato que ele deu ao meu filho. [...] ele danou a vassoura neu" (ROSA)

De boca, a gente teve no ano passado, [...] ele chegou a me enforcar, [...] ele começava a coisar com boca, me ameaçar (MARGARIDA)

Ele tava me ameaçando direto, [...] ele me deu uma cadeirada [...] eu levei 5 pontos na cabeça [...] Ele agredia quebrando as coisas, com muito nome, botando eu pra baixo, muita pressão psicológica, muita pressão psicológica, [...] na cama na hora daquele momento ele mordia minhas costas, cheio de demônio, cheio de cana, mordia minhas costas, levantava minhas pernas pra cima, fazia o que queria com eu [...]. (LÍRIO)

Ele me torturou de todas as maneiras que você possa imaginar. Ele jogava café quente em cima de mim, me jogava prato de comer. Dava em mim de cinto, de fio de energia. Eu apanhei muito de fio de energia, de cabo de DVD, de cabo de bassoura, de chute. Uma vez ele danou tanto minha cabeça na parede que eu desmaiei. Ele quebrou meu celular de machado porque ele dizia que eu tinha outro. [...] ele não me deixava sair pra canto nenhum. [...] ele chutava, chamava de desgraça, rapariga, mas era pancada, era tapa, chutes [...] ele pegou minha cabeça e queria queimar no fogão quando era ligado, aí eu tinha horror. (ORQUÍDEA)

[...] agressão verbal, ciúme possessivo dele, puxão de cabelo, chuto, murro, rasgou minhas roupas, [...] começou a quebrar as coisas dentro de casa [...]. (GIRASSOL)

Fonte: Dados da pesquisa.

Mediante o exposto no Quadro 1, corrobora-se com Saffioti (1999) quando afirma que a violência física, psicológica, sexual e moral não ocorre de forma isolada. Seja qual for a forma assumida pela agressão, a violência 
psicológica, assim como a moral, se entrelaça. Nessas relações, a pressão e a opressão psicológica são constantes, culminando, muitas vezes, na agressão física.

\subsection{Ciclo da violência}

O ciclo da violência foi um modelo desenvolvido pela psicóloga norteamericana Lenore Walker, que buscou explicar como ocorre a violência entre homens e mulheres nas relações íntimas e afetivas. A autora identificou que, apesar das várias faces e especificidades, a violência doméstica acontece dentro de um ciclo que constantemente se repete. Assim, a autora dividiu o ciclo em três fases: construção ou aumento da tensão; tensão máxima; e lua de mel (INSTITUTO MARIA DA PENHA, 2019; WALKER, 1979). Assim, buscou-se analisar a relação de violência, a partir das falas das mulheres, de modo a identificar cada fase do ciclo da violência e como é vivenciada cada uma delas.

A primeira fase do ciclo da violência, denominada de construção ou aumento da tensão, é caracterizada por momentos em que o agressor busca motivos para justificar a violência por meio de ciúmes, agressões verbais, ameaças, destruição de objetos dentro de casa, entre outras formas. As mulheres, por sua vez, na tentativa de pôr fim a violência, acalmar o agressor - que geralmente é o companheiro - utilizam várias estratégias para evitar as agressões.

Quadro 2 - Relatos atinentes à primeira fase do ciclo de violência.

[...] começou a surgir esse negócio de ciúme, aí foi que ele começou a me dar homem, dizendo que eu tava fazendo coisa com outros homem e assim foi, pelo menos foi xingando, mas depois foi que foi aumentando [...] depois que ele xingava muito foi que, ele só ficava resmungando aí ficava enxotando assim, igual tratando a pessoa como cachorro dizer que não queria mais e tudo mais. Eu ficava mal né? Eu ficava péssima, triste [...] eu ficava calada, [...] aí eu deixava ele sozinho e ficava, às vezes, sentava, ficava com a mão no queixo mas eu botava pra chorar. Chorava muito. (ROSA)

[...] ele começava a coisar com boca, me ameaçar. Quando eu pegava um celular, ele já ficava com ciúmes também. (MARGARIDA)

Ele agredia quebrando as coisas, com muito nome, botando eu pra baixo, muita pressão psicológica, muita pressão psicológica, também com violência, quebrando tudo, [...] muitas vezes ele disse, que me matava e me enterrava lá, não tinha quem 
me achasse lá dentro do mato meio mundo de terra. (LÍRIO)

[...] Dia de semana era um amor, mas quando chegava final de semana aí começava: ciúme possessivo, dizia que eu tinha outra pessoa, enxergava alguém dentro de casa sem ter ninguém [...] (GIRASSOL)

Fonte: Dados da pesquisa.

De acordo com o Instituto Maria da Penha (IMP) (2019, não paginado), a tensão dessa primeira fase "[...] pode durar dias ou anos, mas como ela aumenta cada vez mais, é muito provável que a situação levará à Fase 2".

Na segunda fase do ciclo, chamada de tensão máxima, é quando o acúmulo da tensão na fase anterior explode e se efetiva por meio da violência verbal, física, psicológica, moral ou patrimonial. A tensão psicológica é severa e é nesse momento que muitas mulheres decidem pedir ajuda externa para cessar a relação. (INSTITUTO MARIA DA PENHA, 2019, não paginado; WALKER, 1979).

Quadro 1 - Relatos referentes à segunda fase do ciclo de violência.

[...] ele batia muito de mão mesmo, de soco [...] eu procurei o CREAS [...] eu contei tudo que tinha acontecido, eu ainda tava machucada quando eu fui lá, que aqui em mim tava todo machucado que ele danou a vassoura neu, meu braço aqui tava roxo, eu fui peguei e mostrei a ela (ROSA)

[...] ele chegou a me enforcar. Eu começava a chorar. Chorar, não tinha reação pra nada, só chorar! Eu me sentia muito mal. Eu saí escondido [...] Aí eu saí através do pessoal lá que fizeram um esquema, [...] Eu fui na delegacia da mulher fazer o BO e depois fui pra Casa Abrigo. (MARGARIDA)

Uma vez ele danou tanto minha cabeça na parede que eu desmaiei. [...] eu num... eu num aguentava mais. Sabe, chegou um ponto que eu enfrentei ele. Eu nunca tive coragem de enfrentar ele, eu tinha muito medo dele. Eu não tava aguentando mais, [...] Eu só vivia com medo, eu juro, no sábado e no domingo era os piores dias da minha vida.[...] (ORQUÍDEA)

Fonte: Dados da pesquisa.

Percebe-se que foram inúmeros os momentos de tensão máxima na vida das interlocutoras. Nos relatos de Rosa, é possível constatar que a mesma revida as agressões sofridas na tentativa de cessar a violência. Isso acontece porque as mulheres detêm uma parcela menor de poder na relação. De acordo com Maria de Fátima Araújo (2008), embora a dominação masculina seja um privilégio que 
a sociedade patriarcal concede aos homens, nem todos a utilizam da mesma maneira, assim como nem todas as mulheres (re) agem igualmente à dominação.

Apesar da extrema violência, é visível que as interlocutoras, em determinados momentos, conseguiram solicitar ajuda externa e romper com a situação de violência. Todavia, destaca-se que esse não é um processo simples. Em muitos casos, a mulher ameaça fazer a denúncia, mas o agressor finge que está arrependido e promete que a cena não irá se repetir. É, então, que o ciclo da violência passa para a sua fase 3, a chamada de Lua de Mel.

Quadro 4 - Relatos que simulam a terceira fase do ciclo de violência.

[...] Ele começava, ficava bonzinho, depois queria começar tudo de novo. Ele ficava pedindo perdão. Pedia perdão logo, falava: desculpa, não era isso que eu queria fazer... ficava desse jeito, aí depois começava tudo de novo. (MARGARIDA)

[...] quando ele me deu uma cadeirada ele passou 7 meses preso, deu uma cadeirada eu levei 5 pontos na cabeça, aí ele saiu nós começamos do nada, ele disse que ia mudar, eu ainda voltei, mas ainda continuou. [...] desde a primeira vez que eu denunciei ele que ele ficou só 15 dias preso, que era primário, ele tinha matado quando voltou, aí voltou bem caladinho, bem santinho, depois começou fazer de novo, aí me ameaçou com a faca agora, aí eu fui de novo (LÍRIO)

Depois da violência [...] Ele fingia que nada aconteceu. [...] no outro dia era remédio, era meu amor, me chamava de meu amor, era tudo. (GIRASSOL)

Fonte: Dados da pesquisa.

Para Saffioti (2004), embora a violência doméstica tenha seu ciclo, isto é meramente descritivo, pois não induz sequer a atitudes preventivas. A autora defende ser mais adequada a percepção de que a violência contra mulheres se desenvolve em escalada, pois, apesar de esse tipo de violência ter momentos menos tensos, a tendência é que a intensidade aumente, podendo chegar ao seu ápice: o feminicídio.

\subsection{Acesso e busca de informação protagonizado pelas mulheres para romper com a situação de violência}

Para romper com a situação de violência, as mulheres acolhidas na Casa Abrigo percorreram caminhos, se depararam com pessoas que algumas denominaram 'anjas', e, durante o percurso, essas mulheres buscaram e tiveram acesso às informações. Tais informações contribuíram para que elas pudessem contar a 
história de suas vidas. Desta forma, procurou-se saber das interlocutoras a quais informações elas tiveram acesso durante o caminho trilhado até chegar à Casa Abrigo, uma vez que as informações mediadas nessa etapa figuram como divisores de água na vida de cada mulher.

Quadro 5 - Informações recebidas pelas mulheres no processo de busca por ajuda nos órgãos da rede.

[...] eu procurei o CREAS [...] contei tudo que tinha acontecido [...] ela escreveu num papel lá e disseram que era pra eu ficar e perguntaram se eu queria voltar pra casa ou [...] pro abrigo [...], aí eu fui falei assim "eu não vou voltar pra casa porque eu sei que ele vai tá em casa e, se eu voltar pra casa, vai fazer do mesmo jeito, então é melhor eu ir pra outro caminho [...] (ROSA)

Fui no CREAS de Boqueirão falar com a psicóloga [...] Ela (a psicóloga) me sugeriu pra mim fazer um BO, procurar uma Delegacia. Aí eu falei com ela também sobre minha casa... aí ela disse que eu tenho todo direito porque a casa eu construí [...] (MARGARIDA)

Eles [equipe do CRAS e CREAS] que ajeitaram e me encaminharam pra Casa Abrigo. Eu fiz a denúncia por debaixo dos panos. (LÍRIO)

Eles [equipe do conselho tutelar] me mandou procurar uma delegacia da mulher. [...]aí eu procurei uma delegada, ela mandou, ela deu voz de prisão pra ele, mas ele ficou me cercando [...] Ela falou que se eu quisesse tinha uma casa em Campina Grande que acolhia mulheres [...]. No CRAS ele falou assim: eu vou levar você pra uma casa que abriga mulheres de violências, que tem tudo que você precisa lá, pronto, eu não pensei duas vezes, eu corri logo. (ORQUÍDEA)

Do Abrigo, que tem um abrigo pra mim poder ficar. (GIRASSOL)

Fonte: Dados da pesquisa.

Ainda que de forma resumida, os relatos das interlocutoras explicitaram que as informações mediadas nos órgãos influenciaram a decisão de se encaminharem para a CA. No caso de Margarida, verificou-se que o medo de perder o direito à sua casa foi um dos fatores que a fizeram pensar em desistir de ir ao abrigo. Porém, a partir da mediação consciente da psicóloga, ela não se intimidou e foi.

A denúncia geralmente é feita por 'debaixo dos panos', como disse Lírio. Isso porque as mulheres temem por suas vidas caso o agressor tenha conhecimento de suas atitudes. Essas, nesse processo de rompimento, enfrentam antagonismos em cada passo dado na luta para sair da relação. 
Percebe-se o quanto a informação tem potencial de contribuir para a tomada de decisão dos sujeitos, no caso, das mulheres em situação de violência doméstica. Explicita-se que, quando mediada conscientemente, a informação torna-se elemento transformador da realidade e contribui pata construir novos saberes à medida que elas se apropriam das informações (GOMES, 2016, 2017, 2018, 2019). Dessa forma, corrobora-se com Gomes (2016) ao afirmar que a informação é caracterizada como fenômeno ativo no agir humano.

\subsection{Conteúdos informacionais mediados pela $\mathrm{CA}$}

A mediação da informação no âmbito da CA é constante e é delineada de forma dialética, ou seja, há trocas entre as mulheres e a equipe da Casa Abrigo, ambas se influenciam por meio da partilha de saberes em busca de ressignificar a violência que cada mulher sofreu durante a vida. Para Gomes (2014, p. 55-56), "[...] o processo dialético é uma condição fundante da ação mediadora [...]".

A partir dos relatos das interlocutoras, constatou-se que os conteúdos informacionais da CA são gerados por meio da orientação e apoio, do atendimento psicológico e das oficinas ministradas na Casa.

$\mathrm{O}$ atendimento psicológico e a mediação dos conteúdos informacionais são considerados importantes nesse processo, como pode ser observado nas falas de Lírio, Orquídea e Girassol, as quais se reproduz no Quadro 5.

Quadro 5 - Relatos das mulheres sobre o atendimento psicológico na CA.

\begin{tabular}{|c|c|}
\hline $\begin{array}{l}\text { Atendimento } \\
\text { psicológico }\end{array}$ & $\begin{array}{l}\text { [...] eu sofri de um trauma de quando eu era criança [...] porque } \\
\text { eu era assediava [...] e por causa desse trauma que minha visão } \\
\text { era só pra aquilo [parte sexual], aí quando eu cheguei lá [na CA] } \\
\text { a doutora [psicóloga] me ajudou a separar as coisas, que a gente } \\
\text { não é só pra aquilo, a gente é mãe, é mulher, entendeu? [...] ela } \\
\text { me explicou bem direitinho. [...] Quando eu cheguei lá, que fui } \\
\text { nos tratamento, foi que eu fui voltando [...] eu fui chorando, ela } \\
\text { [psicóloga] ia fazendo as sessões de tratamento, eu fui botando } \\
\text { aquilo pra fora, aí foi quando foi aliviando, abrindo, como uma } \\
\text { lavagem cerebral, [...] ela vai dando aquelas orientação, aí você } \\
\text { vai voltando ao normal e vai vendo o erro, as coisas. (LÍRIO) } \\
\text { [...] chama para conversar a psicóloga, Marina, eu adoro ela. Às } \\
\text { vezes eu entro lá em estado apavorante de choro, aí quando eu } \\
\text { converso com ela eu saio leve, ela tira vários peso das minhas }\end{array}$ \\
\hline
\end{tabular}




\begin{tabular}{|l|l|}
\hline $\begin{array}{l}\text { costas só em me ouvir sabe? Ela tem a voz que me acalma" } \\
\text { (ORQUÍDEA) } \\
{[\ldots] \text { as minhas escuta com a psicóloga me edifica muito, muito, }} \\
\text { muito mesmo. (GIRASSOL) }\end{array}$ \\
\hline
\end{tabular}

Fonte: Dados da pesquisa.

Constata-se que a interação entre a equipe e as mulheres acolhidas na CA resulta em uma mediação consciente da informação, alcançando, assim, suas cinco dimensões: dialógica, estética, formativa, ética e política. Nesse processo, as mulheres têm a possibilidade de aprender novos significados para sua vida a partir da apropriação da informação. Os conteúdos informacionais mediados na Casa Abrigo contribuem para o aprimoramento do protagonismo das mulheres, vez que já são consideradas protagonistas por estarem lá, por decidirem tomar a direção de suas vidas e estarem dispostas a lutar por uma vida livre das amarras.

\subsection{Informações acessadas pelas mulheres na Casa Abrigo}

Durante o acolhimento na CA, as mulheres estão em constante interação. Nesse processo, as informações mediadas na casa são fundamentais e de extrema importância para a ressignificação da violência sofrida. Pensando nisso, buscouse saber a quais informações essas mulheres tiveram acesso no período que permaneceram no órgão.

Quadro 6 - Informações acessadas pelas mulheres na Casa Abrigo.

[...] a gente lê livros, lá tem meio mundo de livros, a gente pode jogar, tem jogos, mas assim de informação mesmo só a televisão que vê as coisas na televisão e livro pra gente ler. (ROSA)

A gente sempre tá alí assistindo jornais, aí as informações são pelos jornais. Tem, tem, trata sobre a violência, como a gente tem que fazer né (MARGARIDA)

Da televisão. Só pela tv e as coisas que as meninas conversavam lá. As ajudas delas sim, as informações não, porque eu assistia lá as mulher morrer com as medidas protetivas na bolsa, nós tudinho assistindo que o homem matou a mulher com medida protetiva na bolsa, aí as informações não era muito favorável, porque era muita violência né?! Mas lá, as informações que elas dava sim. É muito apoio psicológico! Financeiro [...] (LÍRIO)

$[\ldots]$ às vezes tem oficina para dizer que você é uma mulher você precisa muito de 
autoestima, sabe? Você, você entra um lixo lá, elas bota você para cima, elas diz você é uma mulher linda, você não precisa depender de ninguém [...] que a mulher tem direito, que você tem que correr atrás do que você quer... essas informações que a gente precisa [...] (ORQUÍDEA)

[...] só a televisão que é nosso amigo, que a gente tá falando da novela todinha, é [...] que tinha que ter mais atividade lá [...] (GIRASSOL)

\footnotetext{
Fonte: Dados da pesquisa.
}

No tocante às informações acessadas na CA, quatro das cinco entrevistadas citaram a televisão como fonte de informação. Percebe-se que as mulheres consideram informação o que é reproduzido pela televisão, e citam jornais e novelas. Rosa cita os livros, mas reforça que informações só acessava pela televisão mesmo. Lírio, apesar de também citar a televisão, considera desfavoráveis os conteúdos reproduzidos nessa fonte, pois assistia, junto às outras abrigadas, casos de mulheres morrendo com medidas protetivas na mão.

Destaca-se, ainda nessa questão, a fala de Orquídea, a qual evidencia as oficinas ocorridas na Casa Abrigo. De fato, durante tal atividade, as informações são de extrema relevância para as mulheres, pois, assim como relata a interlocutora, influenciam positivamente na vida da mulher, como reproduzido na sua fala:

[...] você entra um lixo lá, elas bota você para cima, elas diz você é uma mulher linda, você não precisa depender de ninguém. [...] que a mulher tem direito, que você tem que correr atrás o que você que você quer... essas informações que a gente precisa [...] (ORQUÍDEA).

É durante a promoção de oficinas que as mulheres poderão trabalhar coletivamente a situação de violência vivida e reconstruir sua autoestima (BRASIL, 2003).

Diante disso, ressalta-se a importância da mediação consciente da informação no âmbito da Casa Abrigo para que as mulheres possam colocar em prática o exercício da crítica, favorecendo, assim, o autoconhecimento. Com efeito, elas podem problematizar a situação de violência, desestabilizando seus conhecimentos e favorecendo a construção de novos saberes. 
Sabendo que a CA oferece várias formas de interagir e se comunicar com as acolhidas, constatou-se, no decorrer das entrevistas, uma atividade em especial desenvolvida pelas usuárias durante a estada na casa - a leitura. Dentre algumas fontes de informação, a CA possui uma biblioteca com alguns livros oferecidos para que as mulheres se distraiam no processo de leitura.

Quadro 7 - Acesso à livros pelas mulheres da Casa Abrigo.

[...] a gente ler livros, lá tem meio mundo de livros, [...] pra gente ler. (ROSA)

Ler... só eu e outra lá que gosta de ler... aliás, eu nem gostava de ler, comecei agora dentro da casa e por conta da menina lá que me oferecia um livro e aí eu me interessei, comecei a ler, terminei de ler um livro pequenininho já [...] sobre gostar de si mesmo. Já comecei até outro (MARGARIDA).

Lá eu lia, eu li uns 4 livros ou 5. Até de psicologia eu já tava lendo, porque eu achava a doutora (psicóloga) muito sabida aí eu já tava lendo, mas é muito profundo, dá pra mim não! (LÍRIO)

[...] tem a biblioteca. Leio, bastante! Eu tô lendo mais coisa de criança. Toda historinha: a Bela Adormecida, Chapeuzinho Vermelho, os Três Porquinhos, A Bela e a Fera... todo dia, eu já tenho essas decoradas, mas todo dia eu tenho que ler para eles e eles não gostava não. (ORQUÍDEA)

[...] eu tô lendo lá [...] (GIRASSOL)

Fonte: Dados da pesquisa.

Percebe-se que a leitura não era algo presente no cotidiano das mulheres e que o contato com os livros e o tempo livre que elas tinham no abrigo, conciliados, proporcionaram momentos de prazer e descobertas por meio dessa atividade. Nesse aspecto, Almeida Júnior e Bortolin (2008) consideram a leitura como parte intrínseca do processo de apropriação da informação, no qual o compartilhamento do ato de ler torna-se a 'receita' perfeita para o desencadeamento do gosto pela leitura.

A partir dos relatos, nota-se que há um potencial a ser trabalhado na CA no tocante à leitura. Acredita-se que o desenvolvimento de atividades voltadas para a mediação da leitura pode contribuir para que as mulheres acolhidas na CA desenvolvam o hábito e o gosto pela leitura, refletindo, dessa forma, na educação dos (as) seus (suas) filhos (as), assim como no desenvolvimento do protagonismo social dessas mesmas mulheres. 
Diante disso, ressalta-se a importância da mediação consciente da informação no âmbito da Casa Abrigo para que as mulheres possam colocar em prática o exercício da crítica, favorecendo, assim, o autoconhecimento de modo a fazê-las problematizar a situação de violência, desestabilizando seus conhecimentos e favorecendo a construção de novos saberes.

Corrobora-se com Gomes (2019, p. 17) quando afirma que

A mediação consciente deve ser construída pela área da informação, como elemento fundamental para se alcançar os resultados projetados pelo campo quanto ao cumprimento da sua responsabilidade social $[\ldots]$

Assim, verifica-se que a mediação consciente da informação fortaleceu o protagonismo das mulheres que tiveram acesso ao órgão, de modo que estas pudessem sair da CA empoderadas para estar no mundo como agentes transformadoras da realidade.

\subsection{Alterações no tocante à percepção sobre a violência após a mediação da informação na CA}

Após o acesso à Casa Abrigo e à mediação da informação que ocorre em seu âmbito, verificou-se que a percepção das mulheres acerca da violência doméstica foi alterada, contribuindo para o empoderamento dessas mulheres.

Quadro 8 - Percepção sobre a violência após a mediação da informação na CA.

Mudou assim, mudou que assim, quando eu tava antes de eu tá na Casa Abrigo, que eu tava com o pai dos meus meninos eu me sentia pra baixo, uma pessoa triste, sem vontade de pentear o cabelo, de se arrumar pra sair[...]. Aí, depois que passei pela Casa Abrigo [...], eu disse assim: Poxa, eu agora aqui eu posso fazer o que eu quiser, eu posso cantar, eu posso fazer o que eu quiser aqui, eu posso me sentir livre, eu posso brincar, eu posso conversar, que eu sei que não vai ter ninguém pra me interromper, pra me xingar, pra fazer nada comigo. (ROSA)

Já tenho uma nova visão do que seria a violência, porque começa logo assim com uma coisa pequena, começa logo vamo dizer, por um biliscãozinho, uma tapinha pequena, um xingamento que era o que ele sempre tinha, aí eu disse: não, esse negócio, antes de chegar mais alto não, porque eu vi o jeito dele. [...] “A gente não nasceu pra morrer, ser violentada. A gente nasceu pra viver, pra 
cuidar, pra trabalhar, pra ser livre!" (MARGARIDA)

Mudou, porque agora eu sei distinguir: eu só faço se eu quiser. Não sou mais aquilo como eu cheguei lá, entendeu? É como se eles tivessem abrido meus olhos. [...] lá elas dão a asa que a gente não tem pra voar. Digamos assim, que a gente chega, não tem aquela asa pra voar, e lá o abrigo fornece essa asa pra você ser livre pra voar, entendeu? (LÍRIO)

Eu sei na casa, agora eu sei que tem violência [...] psicológica e moral... de tudo que... tudo que elas me diziam... [...] ela ensina a pessoa. Ensina coisas maravilhosas que você entra como se você fosse um, um bicho e você sai um ser humano, sabe? Era assim que eu entrei, eu era um bicho lá, eu era uma escrava que só servia assim pra ser violentada, estuprada e violentada apanhando e não! Agora descobri que sou uma mulher sabe? (ORQUÍDEA)

Há, mudou! [emocionada] descobri tudo isso [choro], descobri que a gente mulher não é sozinha. [...] conversando com a psicóloga meu pensamento mudou e muito, muito, muito mesmo e vi que a gente não tá sozinha nessa não, tem muitas coisas, muitas coisas mesmo pela gente, então a gente tem que abrir mais a boca e explorar isso, é isso que eu queria. Se eu aguentei esse tempo todinho é por que eu não sabia não, porque se eu soubesse que tinha isso tudo, tudo que você pode ter um telefone e ligar, menina, eu já teria saído há muito tempo, há muito tempo. (GIRASSOL)

Fonte: Dados da pesquisa.

Percebe-se que o aparato informacional oferecido pela CA possibilitou à mulheres aprimorarem seu protagonismo, tornando-se capazes de reconhecer suas capacidades, despertando um novo olhar sobre si mesmas, por meio de um processo dialógico que a mediação da informação envolve e que favorece o exercício da crítica (GOMES, 2019).

Importante frisar que tal processo não ocorre de forma linear, nem automática, mas se consubstancia por um processo dialético. A subjetividade e as condições objetivas influenciam na tomada de decisão, na ressignificação dos esquemas dominantes de gênero e o tempo das mulheres tem que ser respeitado.

\section{Considerações Finais}

Os resultados demonstram que a CA é um espaço crítico, de dialogia, criatividade e alteridade, no qual a mediação da informação é consciente e constante com o intuito de ressignificar a violência vivenciada pelas mulheres acolhidas na Casa. 
O estudo mostra que o processo de mediação da informação acontece de forma dialética entre as profissionais da Casa e as mulheres acolhidas, no qual a informação é produto das partilhas efetivadas nas relações sociais, tornando-se o substrato para compreender a realidade e as possibilidades de transformação.

Percebe-se que os sujeitos envolvidos nesse processo, ou seja, as profissionais que atuam na $\mathrm{CA}$, são protagonistas sociais, pois são conscientes do papel que a informação possui e da sua capacidade de ressignificação nas vidas das mulheres. A mediação dos conteúdos informacionais dinamizados pela Casa Abrigo da Paraíba contribuiu com o desenvolvimento do protagonismo das mulheres, impactando nas suas percepções a respeito da violência doméstica e do rompimento com esse ciclo de violência.

Quanto ao protagonismo das mulheres, este pôde ser constatado na resistência e na luta para romper com a situação de violência desde o momento em que buscaram ajuda e foram direcionadas para a CA. O estudo evidencia que a informação, na condição de conhecimento em estado de compartilhamento (GOMES, 2016; 2017; 2018; 2019), torna-se responsável por contribuir para o desenvolvimento do protagonismo das mulheres que tiveram acesso à CA, uma vez que a troca de experiências possibilita que tanto as usuárias da casa quanto os (as) profissionais que atuam na mesma se tornem sujeitos conscientes e persistam na luta contra a violência doméstica, pois é a partir da ação consciente que o protagonismo social se sustenta. Para tanto, a informação deve ser considerada um elemento central dessas ações.

Sabendo que a violência doméstica contra mulheres é um fenômeno transversal, persistente e multifacetado - que ignora qualquer fronteira de raça/etnia, classes sociais, religião, grau de escolaridade e grau de desenvolvimento econômico, ressalta-se a importância da ampliação dos estudos sobre a violência doméstica em interface com o fenômeno informacional.

Finaliza-se este estudo considerando que o acesso, a mediação e a apropriação da informação são ações fundamentais para que as mulheres desenvolvam seu protagonismo e consigam se empoderar a ponto de romper com o ciclo de violência e se tornar sujeitos conscientes quanto ao seu papel social. Acredita-se que a informação mediada conscientemente pode ser uma das 
vias para promover mudança de mentalidades e reversão dos diversos problemas existentes em nossa sociedade, que ainda é regida pelo machismo, pelo racismo e pela desigualdade social.

\section{Financiamento}

Este artigo é resultado da pesquisa de mestrado em Ciência da Informação, realizada por meio de financiamento da Coordenação de Aperfeiçoamento de Pessoal de Nível Superior (CAPES).

\section{Agradecimentos}

Às mulheres usuárias da Casa Abrigo da Paraíba que se disponibilizaram a compartilhar suas histórias de resistência no enfrentamento à violência.

Às equipes da Secretaria de Estado da Mulher e da Diversidade Humana e da Casa Abrigo pelo acolhimento e apoio, indispensáveis para a concretização do estudo.

\section{Referências}

ALMEIDA JÚNIOR, Oswaldo Francisco de. Leitura, mediação e apropriação da informação. In: SANTOS, Jussara Pereira dos. (org.) A leitura como prática pedagógica na formação do profissional da informação. Rio de Janeiro: Fundação Biblioteca Nacional, 2007.

ALMEIDA JÚNIOR, Oswaldo Francisco de. Mediação da informação: um conceito atualizado. In: BORTOLIN, Sueli; SANTOS NETO, João Arlindo dos; SILVA, Rovilson José. (org.). Mediação oral da informação e da leitura. Londrina: Abecin, 2015.

ALMEIDA JÚNIOR, Oswaldo Francisco de. Profissional bibliotecário: um pacto com o excludente. In: BAPTISTA, Sofia Galvão; MUELLER, Suzana Pinheiro Machado (org.). Profissional da informação: o espaço de trabalho. Brasília: Thesaurus, 2004.

ALMEIDA JÚNIOR, Oswaldo Francisco de; BORTOLIN, Sueli. Mediação da informação e da leitura. In: SILVA, Terezinha Elisabeth da. (org.).

Interdisciplinaridade e transversalidade em Ciência da Informação. Recife: Néctar, 2008.

ARAÚJO, Carlos Alberto Ávila. O que é informação. Belo Horizonte: KMA, 2018. 
ARAÚJO, Maria de Fátima. Gênero e violência contra a mulher: o perigoso jogo de poder e dominação. Psicología para América Latina, México, n. 14, out. 2008.

BARDIN, Lawrence. Análise de conteúdo. Lisboa: Edições 70, 2010.

BORGES, Elinielle Pinto; OLINTO, Gilda; LETA, Jacqueline. Gênero, ciência e contexto regional: reflexões sobre resultados acadêmicos da pós-graduação no Brasil. In: ENCONTRO NACIONAL DE PESQUISA EM CIÊNCIA DA INFORMAÇÃO, 15., 2014. Anais [...]. Belo Horizonte: ANCIB, 2014.

BRASIL. Lei $\mathrm{n}^{\circ}$. 11.340, de 7 de agosto de 2006. Lei Maria da Penha. Dispõe sobre a violência doméstica e familiar contra a mulher. Diário Oficial da União, Poder Legislativo, Brasília, DF, 8 ago. 2006.

BRASIL. Secretaria Especial de Políticas para as Mulheres - SPM. Programa de Prevenção, Assistência e Combate à Violência Contra a Mulher - Plano Nacional: diálogos sobre violência doméstica e de gênero: construindo políticas públicas. Brasília, DF: SPM, 2003.

FARIAS, Maria Giovanna Guedes. Análise da produção, implementação e avaliação de um modelo de mediação da informação no contexto de uma comunidade urbana. 2014. 283 f. Tese (Doutorado em Ciência da Informação) - Universidade Federal da Bahia, Salvador, 2014.

FONSECA, João José Saraiva da. Metodologia da pesquisa científica. Fortaleza: UEC, 2002.

GOMES, Henriette Ferreira. A dimensão dialógica, estética, formativa e ética da mediação da informação. Informação \& Informação, Londrina, v. 19, n. 2, p. 46-59, maio/ago. 2014.

GOMES, Henriette Ferreira. Comunicação e Informação: relações dúbias, complexas e intrínsecas. In: MORIGI, Valdir; JACKS, Nilda; GOLIN, Cida. Epistemologia, comunicação e informação. Porto Alegre: Sulina, 2016.

GOMES, Henriette Ferreira. Mediação da informação e protagonismo social: relações com vida ativa e ação comunicativa à luz de Hannah Arendt e Jürgen Habermas. In: GOMES, Henriette Ferreira; NOVO, Hildenise Ferreira (org.). Informação e protagonismo social. Salvador: EDUFBA, 2017.

GOMES, Henriette Ferreira. Protagonismo sócio-informacional na saúde coletiva. Informação em Pauta, Fortaleza, v. 3, n. especial, p. 47-61, 2018.

GOMES, Henriette Ferreira. Protagonismo social e mediação da informação. Logeion: Filosofia da informação, Rio de Janeiro, v. 5, n. 2, p. 10-21, mar./ago. 2019. 
INSTITUTO MARIA DA PENHA. Ciclo da violência. Fortaleza: Instituto Maria da Penha, 2019.

LOUSADA, Mariana. A mediação da informação na Teoria Arquivística. 2015. 135 f. Tese (Doutorado em Ciência da Informação) - Faculdade de Filosofia e Ciências, Universidade Estadual Paulista, Marília, 2015.

PERROTTI, Edmir. Sobre informação e protagonismo cultural. In: GOMES, Henriette Ferreira; NOVO, Hildenise Ferreira (org.). Informação e protagonismo social. Salvador: EDUFBA, 2017.

PERROTTI, Edmir; PIERUCCINI, Ivete. Infoeducação: saberes e fazeres da contemporaneidade. In: LARA; Marilda Lopes Ginez de; FUGINO, Asa; NORONHA, Daisy Pires (org.). Informação e Contemporaneidade: Perspectivas. Recife: NÉCTAR, 2007.

SAFFIOTI, Heleieth I. B. Gênero, patriarcado, violência. São Paulo: Fundação Perseu Abramo, 2004.

SAFFIOTI, Heleieth I. B. Já se mete a colher em briga de marido e mulher. São Paulo em Perspectiva, São Paulo, v. 13, n. 4, p. 82-91, dez. 1999.

SANTOS NETO, João Arlindo dos. Mediação implícita da informação no discurso dos bibliotecários da Biblioteca Central da Universidade Estadual de Londrina (UEL). 2014. 193 f. Dissertação (Mestrado em Ciência da Informação) - Faculdade de Filosofia e Ciências, Universidade Estadual Paulista, Marília, 2014.

TAVARES, Márcia Santana; SARDENBERG, Cecília M. B.; GOMES, Márcia Queiroz de C. Feminismo, estado e políticas de enfrentamento à violência contra mulheres: monitorando a lei Maria da Penha. Labrys Estudos Feministas, Florianópolis, jun./dez. 2011.

WAISELFISZ, Julio Jacobo. Mapa da violência 2015: Homicídio de mulheres no Brasil. Brasília: FLACSO, 2015.

WALKER, Leonore. The battered woman. New York: Harper and How, 1979.

\section{The mediation of information in the Shelter House of Paraíba: the protagonismo of women in confronting domestic violence}

\footnotetext{
Abstract: The research aims to verify how the mediation of information at Casa Abrigo da Paraíba favored the role of women to break with the situation of domestic violence. As for the methodology, the study has a descriptive
} 
character, with a qualitative approach, for whose development the case study was used as a strategy. The research field was Casa Abrigo da Paraíba and the interlocutors were women who accessed the organ. In the collection, we used the in-depth interview, carried out with women who are deprived of their freedom, and who had to resort to a shelter to stay alive. The data were analyzed using content analysis. The results demonstrate that Casa Abrigo da Paraíba is a critical space, one of dialogue, creativity and alterity, in which the mediation of information is conscious and constant in order to resignify the violence experienced by the women welcomed in the House. It appears that the mediation of informational content promoted by Casa Abrigo da Paraíba contributed to the development of the role of women, impacting on perceptions about domestic violence and breaking the cycle of violence. As for the protagonism of women, this could be seen in the resistance and struggle to break the situation of violence from the moment they sought help and were directed to the agency. It ends by considering that consciously mediated information can be one of the ways to change mentalities and reverse the various problems that exist in our society, which is still governed by machismo, racism and social inequality.

Keywords: Information Mediation. Social Protagonism. Shelter House. Women. Domestic violence.

Recebido: $26 / 05 / 2020$

Aceito: $21 / 09 / 2020$

\section{Declaração de Autoria}

Concepção e elaboração do estudo: Aurekelly e Gisele

Coleta de dados: Aurekelly

Análise e discussão de dados: Aurekelly e Gisele

Redação e revisão do manuscrito: Aurekelly

\section{Como Citar}

SILVA, Aurekelly Rodrigues da; CÔRTES, Gisele Rocha. A mediação da informação na Casa Abrigo da Paraíba: o protagonismo das mulheres no enfrentamento à violência doméstica. Em Questão, Porto Alegre, v. 27, n. 3, p. 94-119, 2021. Doi: http://dx.doi.org/10.19132/1808-5245273.94-119

\footnotetext{
${ }^{1} \mathrm{Na}$ visão de Lisboa (2010, p. 73), “[...] a equidade de gênero se refere à distribuição justa de direitos, oportunidades, recursos, responsabilidades, tarefas entre os gêneros, respeitando as diferenças entre homens e mulheres. Pressupõe, ainda, ações para dotar as mulheres dos instrumentos, recursos e mecanismos necessários para participar e deixá-las preparadas para exercer cargos, propor e participar das decisões que lhe dizem respeito".
} 
${ }^{2} \mathrm{O}$ autor supracitado é pioneiro nos estudos sobre mediação da informação (ARAÚJO, 2018) e trabalha assiduamente a temática a fim de solidificar o conceito na CI, de modo que se tornou um dos nomes mais citados nos trabalhos de mediação na área.

${ }^{3}$ É parceira da Secretaria Estadual de Segurança Pública do Estado para garantir segurança em período integral. Seu acesso é restrito e o endereço é secreto. 